\title{
Mutual Passivation of Electrically Active and Isovalent Impurities
}

K. M. Yu *, W. Walukiewicz*, J. Wu*, D. E. Mars ${ }^{\dagger}$, D. R Chamberlin†, M. A.

Scarpulla*‡, O. D. Dubon* $*$, and J. F. Geisz $\$$

* Materials Sciences Division, Lawrence Berkeley National Laboratory, Berkeley, CA

$\dagger$ Agilent Laboratories, 3500 Deer Creek Road, Palo Alto, CA 94304

$\ddagger$ Department of Materials Science and Engineering, University of California, Berkeley, California 94720

§ National Renewable Energy Laboratory, Golden, Colorado 80401

\begin{abstract}
We have demonstrated the existence of an entirely new effect in the $\mathrm{GaN}_{\mathrm{x}} \mathrm{As}_{1-\mathrm{x}}$ alloy system in which the substitutional donor $\mathrm{Si}$ and the isovalent atom $\mathrm{N}$ passivate each other's electronic activity. This mutual passivation occurs in Si doped $\mathrm{GaN}_{\mathrm{x}} \mathrm{As}_{1-\mathrm{x}}$ through the formation of nearest neighbor $\mathrm{Si}_{\mathrm{Ga}}-\mathrm{N}_{\mathrm{As}}$ pairs, is thermally stable up to $950^{\circ} \mathrm{C}$, and correlates with an increase in a sub-band gap, deep level emission at $0.8 \mathrm{eV}$. Consequently, Si doping in $\mathrm{GaN}_{x} \mathrm{As}_{1-\mathrm{x}}$ under equilibrium conditions results in a highly resistive $\mathrm{GaN}_{\mathrm{x}} \mathrm{As}_{1-\mathrm{x}}$ layer with the fundamental band gap governed by a net "active" $\mathrm{N}$, roughly equal to the total $\mathrm{N}$ content minus the Si concentration. Such mutual passivation is expected to be a general phenomenon for electrically active dopants and localized state impurities that can form nearest neighbor pairs.
\end{abstract}


Highly mismatched semiconductor alloys (HMAs) in which a small fraction of the metallic anions is replaced by more electronegative elements have become an important class of materials as they exhibit dramatic changes in electronic properties from the host materials giving rise to many potential technological applications. ${ }^{1-3} \mathrm{~A}$ notable and well-studied example is the $\mathrm{GaN}_{\mathrm{x}} \mathrm{As}_{1-\mathrm{x}} \mathrm{HMA}$, in which a strong band gap reduction by as much as $180 \mathrm{meV}$ per mole percent of $\mathrm{N}$ (i.e. for $\mathrm{x}=0.01$ ) has been observed. ${ }^{3}$ The unusual properties of HMAs have been successfully described by the recently proposed band anticrossing (BAC) model. ${ }^{1,4}$ The BAC model suggests that an anticrossing interaction between localized states of the foreign electronegative element and the extended states of the host semiconductor matrix splits the conduction band into two subbands. The downward shift of the lower subband is responsible for the reduction of the fundamental band gap while optical transitions from the valence band to the upper subband account for the high-energy edge. This anticrossing interaction also leads to a considerable flattening of the lower subband near its minimum which in turn results in a large increase of the electron effective mass. ${ }^{1,5}$ Recent reports have shown that the modified conduction band in $\mathrm{GaN}_{\mathrm{x}} \mathrm{As}_{1-\mathrm{x}}$ enables an enhancement in the maximum achievable free electron concentration $n_{\max }$ by a factor of five as compared to GaAs. ${ }^{6,7}$ In a heavily Se-doped $\mathrm{Ga}_{1-3 \mathrm{x}} \mathrm{In}_{3 \mathrm{x}} \mathrm{N}_{\mathrm{x}} \mathrm{As} \mathrm{s}_{1-\mathrm{x}}$ alloy thin film with only $3.3 \%$ of nitrogen, maximum free electron concentration $n_{\max }$ as high as $7 \times 10^{19} \mathrm{~cm}^{-3}$ was achieved, more than one order of magnitude larger than that of GaAs. ${ }^{6}$

Polimeni et al. has shown that the introduction of hydrogen into $\mathrm{Ga}_{1-\mathrm{y}} \mathrm{In}_{\mathrm{y}} \mathrm{N}_{\mathrm{x}} \mathrm{As}_{1-\mathrm{x}}$ and $\mathrm{GaN}_{\mathrm{x}} \mathrm{As}_{1-\mathrm{x}}$ thin films and quantum wells restores the band gap energy to the values of the materials without $\mathrm{N} .{ }^{8,9}$ This was attributed to the formation of $\mathrm{N}-\mathrm{H}$ bonds that resulted in the passivation of $\mathrm{N}$. Subsequent thermal annealing up to $550^{\circ} \mathrm{C}$ dissociates the $\mathrm{N}-\mathrm{H}$ bond, completely restoring the band gaps of the diluted nitride layers to their values before hydrogenation. The effects of hydrogenation in this material are very similar to the wellknown $\mathrm{H}$ passivation of electrically active dopants in 
semiconductors. ${ }^{10}$ In this paper we demonstrate the existence of an entirely new effect in which an electrically active substitutional $\mathrm{Si}$ donor and an isovalent $\mathrm{N}$ atom passivate each other's electronic effects. The mutual passivation occurs in Si doped $\mathrm{GaN}_{\mathrm{x}} \mathrm{As}_{1-\mathrm{x}}$ through the formation of nearest neighbor $\mathrm{Si}_{\mathrm{Ga}}-\mathrm{N}_{\mathrm{As}}$ pairs when the samples are annealed under conditions such that the diffusion length of $\mathrm{Si}$ is greater than or equal to the average distance between $\mathrm{Si}$ and $\mathrm{N}$ atoms. The passivation is thermally stable up to $950^{\circ} \mathrm{C}$ and correlates with an increase in a sub-band gap, deep level emission at $0.8 \mathrm{eV}$.

Two types of $\mathrm{GaN}_{\mathrm{x}} \mathrm{As}_{1-\mathrm{x}}$ layers were prepared for this study: epitaxial thin films grown by molecular beam epitaxy (MBE) or metal organic vapor phase epitaxy (MOVPE) and N ion synthesized layers. Si dopants were introduced either during the growth or in a post growth Si ion implantation process. The ion synthesized or epitaxially grown samples were either rapid thermally annealed (RTA) or pulsed laser annealed (PLA). RTA was performed in a flowing $\mathrm{N}_{2}$ ambient in the temperature range of $550-950^{\circ} \mathrm{C}$ for $1-120 \mathrm{~s}$ with the sample surface protected by a blank GaAs wafer. Pulsed laser annealing (PLA) was carried out in air using a $\mathrm{XeCl}$ excimer laser $(\lambda=308 \mathrm{~nm})$ with pulse duration $\sim 30 \mathrm{~ns}$ and laser fluences of 0.35 - to $0.79 \mathrm{~J} / \mathrm{cm}^{2}$.

The resistivity and free carrier concentration in the samples were measured by the Hall effect technique in the Van de Pauw geometry. Fig. 1 shows the results of Hall effect measurements on a series of MBE-grown $\mathrm{GaN}_{0.015} \mathrm{As}_{0.985}: \mathrm{Si}$ and GaAs:Si samples after RTA for $10 \mathrm{sec}$ in the temperature range of $650-950^{\circ} \mathrm{C}$. The Si concentration estimated from the growth conditions in these samples is $\sim 1.6 \times 10^{19} \mathrm{~cm}^{-3}$. To achieve high donor activation efficiency the samples were typically grown at substrate temperature lower than normal GaAs MBE growth. ${ }^{11}$ For the thin film without N, only a slight increase in the resistivity is observed as the RTA temperature increases, corresponding to a decrease in electron concentration, $n$ from $1.6 \times 10^{19}$ to $8 \times 10^{18} \mathrm{~cm}^{-3}$ (Fig. 1(b)). Such a decrease in electron concentration in GaAs is in agreement with the amphoteric native defect model that suggests that the equilibrium maximum electron concentration $n$ is in 
the range of $10^{18}-10^{19} \mathrm{~cm}^{-3} \cdot{ }^{12,13}$ The fact that the as- grown GaAs:Si has a high $n$ equals to $1.6 \times 10^{19} \mathrm{~cm}^{-3}$ indicates that this sample is far from thermodynamic equilibrium, probably due to the highly non-equilibrium nature of the MBE growth process. ${ }^{11}$

In striking contrast to the behavior of the GaAs:Si thin film, the resistivity of the $\mathrm{GaN}_{0.015} \mathrm{As}_{0.985}$ :Si thin films rises drastically at RTA temperatures higher than about $800^{\circ} \mathrm{C}$. Correspondingly the free electron concentration in the $\mathrm{GaN}_{0.015} \mathrm{As}_{0.985}: \mathrm{Si}$ thin films drops from $1.1 \times 10^{19} \mathrm{~cm}^{-3}$ in the as-grown film to $3 \times 10^{17} \mathrm{~cm}^{-3}$ in the film RTA at $950^{\circ} \mathrm{C}$. In fact, RTA at $950^{\circ} \mathrm{C}$ for longer time durations further reduces the free electron concentration in the $\mathrm{GaN}_{0.015} \mathrm{As}_{0.985}$ sample (to $n<10^{15} \mathrm{~cm}^{-3}$ for $120 \mathrm{sec}$ ) while no significant change is observed in the GaAs sample.

The reduced electrical activity of $\mathrm{Si}$ donors in $\mathrm{GaN}_{\mathrm{x}} \mathrm{As}_{1-\mathrm{x}}$ alloys can be attributed to the formation of nearest neighbor $\mathrm{Si}_{\mathrm{Ga}}-\mathrm{N}_{\mathrm{As}}$ pairs from the $\mathrm{Si}$ donors and isovalent $\mathrm{N}$ atoms. The highly electronegative $\mathrm{N}$ atom strongly binds the fourth valence electron of $\mathrm{Si}$, preventing it from acting as a hydrogenic donor. Such an explanation suggests that because of the localized nature of the $\mathrm{N}$-states in $\mathrm{GaN}_{\mathrm{x}} \mathrm{As}_{1-\mathrm{x}}$ the passivation is limited to group IV donors that occupyGa sites.

To test this hypothesis we have investigated the annealing behavior of a Se doped MOVPE-grown $\mathrm{GaN}_{0.012} \mathrm{As}_{0.988}$ thin film with Se concentration of $\sim 4 \times 10^{20} \mathrm{~cm}^{-3}$. As is shown in Fig. 1 (b) only a small decrease of electron concentration is observed in this Se doped sample after annealing at $950^{\circ} \mathrm{C}$, similar to the behavior found in the $\mathrm{GaAs}: \mathrm{Si}$ sample. We also note that no passivation effects can be observed for $\mathrm{S}$ donors in $\mathrm{S}$ implanted $\mathrm{GaN}_{\mathrm{x}} \mathrm{As}_{1-\mathrm{x}}$ thin films. ${ }^{7}$ This result clearly supports our conjecture that $\mathrm{N}$ in $\mathrm{GaN}_{\mathrm{x}} \mathrm{As}_{1-\mathrm{x}}$ cannot passivate group VI donors because $\mathrm{N}_{\mathrm{As}}$ does not reside in the nearest neighbor of a $\mathrm{VI}_{\mathrm{As}}$ donor (such as $\mathrm{Se}$ or $\mathrm{S}$ ).

The results in Fig. 1 indicate that the thermally activated passivation has a relatively well-defined onset temperature of about $800^{\circ} \mathrm{C}$. This can be understood assuming that the passivation process is controlled by the diffusion of randomly 
distributed $\mathrm{Si}$ atoms to a $\mathrm{Ga}$ site with a $\mathrm{N}_{\mathrm{As}}$ nearest neighbor. It has been shown that the diffusion constant of $\mathrm{Si}$ in GaAs is well described by the formula $\mathrm{D}=\mathrm{D}_{0} \exp \left(-\mathrm{E}_{\mathrm{a}} / \mathrm{kT}\right)$ with $\mathrm{D}_{0}=4 \times 10^{-4} \mathrm{~cm}^{2}$ and $\mathrm{E}_{\mathrm{a}}=2.45 \mathrm{eV} .{ }^{14}$ Using this formula, we find that annealing for $10 \mathrm{sec}$ at $780^{\circ} \mathrm{C}$ is required for $\mathrm{Si}$ atom diffusion length $\mathrm{L}_{D}=(\mathrm{Dt})^{1 / 2}$ to be equal to the average distance of $\sim 9 \AA$ from a Si atom to its nearest $\mathrm{N}$ site in $\mathrm{GaN}_{0.015} \mathrm{As}_{0.985}$. This temperature is very close to the observed onset of the Si passivation shown in Fig. 1. It should be noted that any rearrangement of $\mathrm{N}$ atoms should be negligible because of their much higher diffusion activation energy of $3.6 \mathrm{eV}{ }^{15}$

Further support for the notion of the Si diffusion controlled passivation is provided by thermal annealing of a thin film $\mathrm{Ga}_{1-\mathrm{y}} \operatorname{In}_{\mathrm{y}} \mathrm{N}_{\mathrm{x}} \mathrm{As} \mathrm{s}_{1-\mathrm{x}}$ :Si alloy $(\mathrm{x}=0.017, \mathrm{y}=0.07)$ with a much higher Si concentration of $\sim 9 \times 10^{19} \mathrm{~cm}^{-3}$ and an electron concentration of $3 \times 10^{19} \mathrm{~cm}^{-3}$. As is shown in Fig. 1(b), the onset of the passivation in this sample with much higher Si concentration occurs at a lower temperature of about $700^{\circ} \mathrm{C}$. Since the $\mathrm{Si}$ diffusion is mediated by triply negatively charged gallium vacancies $V_{G a}^{3-}$ the activation energy for the diffusion process depends on the Fermi energy. ${ }^{16}$ The increase of the electron concentration from $1.1 \times 10^{19} \mathrm{~cm}^{-3}$ in the $\mathrm{GaN}_{0.015} \mathrm{As}_{0.985}$ sample to $3 \times 10^{19} \mathrm{~cm}^{-3}$ in the $\mathrm{Ga}_{0.97} \mathrm{In}_{0.03} \mathrm{~N}_{0.01} \mathrm{As}_{0.99}$ sample shifts the Fermi energy by $\Delta \mathrm{E}_{\mathrm{F}}=0.09 \mathrm{eV}$, resulting in a reduction of the diffusion activation energy by $3 \Delta \mathrm{E}_{\mathrm{F}}=0.27 \mathrm{eV}$, or $\mathrm{E}_{\mathrm{a}}=2.18 \mathrm{eV}$. Using this value of $E_{a}$, we obtain a Si diffusion length that equals the average separation of $8.6 \AA$ between $\mathrm{Si}$ donors and nearest $\mathrm{N}$ atoms for annealing at about $670^{\circ} \mathrm{C}$ for $10 \mathrm{sec}$. This temperature is again in very good agreement with the observed onset of the Si passivation in the $\mathrm{Ga}_{0.97} \mathrm{In}_{0.03} \mathrm{~N}_{0.01} \mathrm{As}_{0.99}$ alloy film.

The above results provide compelling evidence that the formation of $\mathrm{Si}_{\mathrm{Ga}}-\mathrm{N}_{\mathrm{As}}$ is responsible for the elimination of the shallow dopant behavior of Si atoms. However, since the isovalent nitrogen is responsible for a massive modification of the electronic structure of $\mathrm{GaN}_{\mathrm{x}} \mathrm{As}_{1-\mathrm{x}}$ alloys, ${ }^{1,4}$ the extent to which the formation of these pairs affects the role of $\mathrm{N}$ atoms in the alloys is investigated. The most straightforward and reliable 
way to determine the concentration of active $\mathrm{N}$ atoms is to measure the width of the fundamental band gap, which is related to the concentration of the active $\mathrm{N}$ atoms through the expression derived from the band anticrossing model. ${ }^{1,4}$ The band gap of the films was measured using photomodulated reflectance (PR) at room temperature using a chopped $\mathrm{HeCd}$ laser beam $(\lambda=442 \mathrm{~nm}$ or $325 \mathrm{~nm}){ }^{2}$ Fig. 2 shows the effect of thermal annealing on the band gap of two $\mathrm{Ga}_{0.93} \mathrm{In}_{0.07} \mathrm{~N}_{0.017} \mathrm{As}_{0.983}$ :Si samples with $\mathrm{Si}$ concentration of $\sim 1.6 \times 10^{19}$ and $9 \times 10^{19} \mathrm{~cm}^{-3}$. We note that the electrical behavior of the sample with [Si] 1.6x $10^{19} \mathrm{~cm}^{-3}$ as a function of annealing is identical to that of the $\mathrm{GaN}_{\mathrm{x}} \mathrm{As}_{1-\mathrm{x}}$ :Si sample shown in Fig. 1. The annealing has a very small effect on the band gap of the sample doped with lower Si concentration. This is not unexpected due to the relatively low total Si conc entration of $\sim 1.6 \times 10^{19} \mathrm{~cm}^{-3}$ (corresponding to only $0.07 \%$ molar fraction). Passivation of this low concentration of $\mathrm{N}$ atoms would change the band gap by less than $10 \mathrm{meV}$.

In contrast, thermal annealing results in a considerable widening of the energy gap in the $\mathrm{Ga}_{1-\mathrm{y}} \mathrm{In}_{\mathrm{y}} \mathrm{N}_{\mathrm{x}} \mathrm{As}_{1-\mathrm{x}}$ sample doped with $\sim 9 \mathrm{x} 10^{19} \mathrm{~cm}^{-3} \mathrm{Si}$ atoms. Annealing of the sample at $950^{\circ} \mathrm{C}$ increases the gap by about $35 \mathrm{meV}$. This increase in band gap corresponds to a reduction of the concentration of the active $\mathrm{N}$ atoms by $8 \times 10^{19} \mathrm{~cm}^{-3}$. The reduction in active $\mathrm{N}$ is very close to the total $\mathrm{Si}$ concentration. This confirms that the formation of $\mathrm{Si}_{\mathrm{Ga}}-\mathrm{N}_{\mathrm{As}}$ pairs results in a mutual passivation of both species: it eliminates the electrical activity of Si donors and deactivates $\mathrm{N}$ as the isovalent dopant. As has been discussed above it appears that the $\mathrm{Si}_{\mathrm{Ga}}-\mathrm{N}_{\mathrm{As}}$ pair strongly binds the fourth valence electron of $\mathrm{Si}$, transforming this shallow hydrogenic donor into a deep localized center.

This scenario of the passivation process is further corroborated by photoluminescence (PL) measurements on the $\mathrm{GaN}_{0.015} \mathrm{As}_{0.985}$ :Si sample. The PL signals were generated in the backscattering geometry by excitation with the $515 \mathrm{~nm}$ line of an argon laser. The signals were then dispersed by a SPEX 1680B monochromator and detected by a liquid-nitrogen cooled Ge photodiode. Fig. 3 shows room temperature 
$(295 \mathrm{~K})$ and low temperature $(12 \mathrm{~K})$ PL spectra for samples annealed at different temperatures. The room temperature PL spectrum of the as-grown sample shows a broad band edge peak at $1.15 \mathrm{eV}$ and weaker deep luminescence feature at about $0.8 \mathrm{eV}$. It is clearly seen from the results in Fig. 3 that annealing at temperatures higher than $800^{\circ} \mathrm{C}$ results in a strong increase of the intensity of the low energy PL peak at $0.8 \mathrm{eV}$. At the same time the intensity of the band edge PL is drastically reduced and is not detectable in the sample annealed at $950^{\circ} \mathrm{C}$. Comparing these results with the results of Fig. 1 we find a clear correlation between decreased electrical activity of Si donors and an increased deep level luminescence, strongly suggesting that the deep PL is associated with $\mathrm{Siga}_{\mathrm{Ga}}-\mathrm{N}_{\mathrm{As}}$ pairs.

The discovered mutual passivation of $\mathrm{Si}$ and $\mathrm{N}$ in GaAs represents a unique effect that could be used to locally control the band structure and/or electrical properties of materials. In order to test the feasibility of this approach we have also studied the mutual passivation in $\mathrm{N}$ and Si co-implanted GaAs. Recently we have reported the successful synthesis of $\mathrm{GaN}_{\mathrm{x}} \mathrm{As}_{1-\mathrm{x}}$ thin films by $\mathrm{N}$-implantation in $\mathrm{GaAs}$ followed by a combination of pulsed laser annealing (PLA) and RTA. ${ }^{17}$ Using this method we have synthesized $\mathrm{GaN}_{\mathrm{x}} \mathrm{As}_{1-\mathrm{x}}$ layer with $\mathrm{x}$ as high as 0.016 . Using the same technique we formed Si doped $\mathrm{GaN}_{\mathrm{x}} \mathrm{As}_{1-\mathrm{x}}$ layers by sequential implantation of $\mathrm{N}$ and $\mathrm{Si}$ ions into a semi-insulating GaAs wafer at room temperature followed by PLA and RTA. The multiple-energy $\mathrm{N}+\mathrm{Si}$ implantation created a $\sim 0.3 \mu \mathrm{m}$ thick layer with $\mathrm{N}$ concentrations $\sim 3.6 \times 10^{20} \mathrm{~cm}^{-3}$. The top $\sim 0.25 \mu \mathrm{m}$ of this layer was implanted with a uniform Si concentration of $\sim 6.3 \times 10^{19}$ $\mathrm{cm}^{-3}$.

Fig. 4 shows the PR spectra from the $\mathrm{Si}$ doped and undoped $\mathrm{GaN}_{\mathrm{x}} \mathrm{As}_{1-\mathrm{x}}$ samples after PLA with a laser fluence of $0.4 \mathrm{~J} / \mathrm{cm}^{2}$ followed by RTA at $950^{\circ} \mathrm{C}$ for $10 \mathrm{~s}$. The undoped layer was synthesized by the $\mathrm{N}$ implantation alone. The sample implanted with $\mathrm{N}$ alone showed a PR transition at $1.25 \mathrm{eV}$, a band gap reduction of $160 \mathrm{meV}$ compared to the GaAs substrate. Using the BAC model, this corresponds to a GaN mole fraction (x) 
of 0.0088. PR measurement on the Si doped $\mathrm{GaN}_{\mathrm{x}} \mathrm{As}_{1-\mathrm{x}}$ sample reveals a band gap of $1.29 \mathrm{eV}$, corresponding to $\mathrm{x}=0.006$. The larger band gap of the $\mathrm{Si}$ doped $\mathrm{GaN}_{\mathrm{x}} \mathrm{As}_{1-\mathrm{x}}$ layers (by $40 \mathrm{meV}$ ) as compared to the undoped sample shown in Fig. 4 can be attributed to a reduction of $\mathrm{N}$ concentration by $\sim 6 \times 10^{19} \mathrm{~cm}^{-3}$, a value similar to the implanted $\mathrm{Si}$ concentration in the layer. At the same time, electrical measurements reveal that the $\mathrm{N}+\mathrm{Si}$ layer is very resistive with contact resistance in the $\mathrm{M} \Omega$ range indicating that all $\mathrm{Si}$ donors are passivated by forming $\mathrm{Si}_{\mathrm{Ga}}-\mathrm{N}_{\mathrm{As}}$ pairs.

In conclusion, we have discovered the mutual passivation for electrically active (Si) and isovalent $(\mathrm{N})$ in GaAs. Our experimental results provide strong evidence that this mutual passivation is due to the formation of $\mathrm{Si}_{\mathrm{Ga}}-\mathrm{N}_{\mathrm{As}}$ bonds that are thermally stable. Consequently, Si doping in $\mathrm{GaN}_{\mathrm{x}} \mathrm{As}_{1-\mathrm{x}}$ results in a highly resistive $\mathrm{GaN}_{\mathrm{x}} \mathrm{As}_{1-\mathrm{x}}$ layer with fundamental band gap governed by a net "active" $\mathrm{N}$ (roughly equal to the total $\mathrm{N}$ content minus the Si concentration). We expect that such mutual passivation is a general phenomenon for electrically active hydrogenic dopants and impurities that form localized states when these species reside in cation and anion sites of the semiconductor so that they can form nearest neighbor passivating pairs, e.g. other group IV donors (Ge and $\mathrm{Sn}$ ) in $\mathrm{GaN}_{\mathrm{x}} \mathrm{As}_{1-\mathrm{x}}$. This mutual passivation of electrically active and isovalent impurities in compound semiconductors can be exploited for electrical isolation, band gap engineering and quantum confinement. This also provides a unique opportunity for the fabrication of both planar and three-dimensional novel structures by the selective implantation of either one or both species.

The authors thanks M. R. Pillai, M. J. Aziz for their assistance in laser annealing, and J. Beeman for ion implantation. This work was supported by the Director, Office of Science, Office of Basic Energy Sciences, Division of Materials Sciences and Engineering, of the U. S. Department of Energy under Contract No. DE-AC0376 SF00098. 


\section{REFERENCES}

1. Walukiewicz, W. et al., Interaction of Localized Electronic States with the Conduction Band: Band Anticrossing in II-VI Semiconductor Ternaries, Phys. Rev. Lett. 85, 1552-1555 (2000)

2. $\mathrm{Yu}, \mathrm{K}$. M. et al., Band anticrossing in group II-Ox-VI1-x highly mismatched alloys: $\mathrm{Cd}_{1-\mathrm{y}} \mathrm{Mn}_{\mathrm{y}} \mathrm{O}_{\mathrm{x}} \mathrm{Te}_{1-\mathrm{x}}$ quaternaries synthesized by $\mathrm{O}$ ion implantation, Appl. Phys. Lett. 80, 1571-1573 (2002)

3. Semiconductor Science and Technology 17, 2002, Special Issue: III-N-V Semiconductor Alloys.

4. Shan, W. et al., Band Anticrossing in GaInNAs Alloys, Phys. Rev. Lett. 82, 12211224 (1999)

5. Skierbiszewski, C. et al., Large, nitrogen-induced increase of the electron effective mass in $\mathrm{In}_{\mathrm{y}} \mathrm{Ga}_{1-\mathrm{y}} \mathrm{N}_{\mathrm{x}} \mathrm{As}_{1-\mathrm{x}}$, Appl. Phys. Lett. 76, 2409-2411 (2000)

6. Yu, K. M. et al., Nitrogen-induced increase of the maximum electron concentration in group III-N-V alloys, Phys. Rev. B61, R13337-R13340 (2000)

7. Yu, K. M. et al., Nitrogen-induced enhancement of the free electron concentration in sulfur implanted $\mathrm{GaN}_{\mathrm{x}} \mathrm{As}_{1-\mathrm{x}}$, Appl. Phys. Lett. 77, 2858-2860 (2000)

8. Polimeni, A. et al., Effect of hydrogen on the electronic properties of $\operatorname{In}_{\mathrm{x}} \mathrm{Ga}_{1-\mathrm{x}} \mathrm{As}_{1-}$ y $\mathrm{N}_{\mathrm{y}} / \mathrm{GaAs}$ quantum wells, Phys. Rev. B63, 201304 (2001).

9. Polimeni, A. et al., Role of hydrogen in III-N-V compound semiconductors, Semicond. Sci. Technol. 17, 797-802 (2002).

10. See, for example, Pankove, J. I. and Johnson, N. M. ed., Hydrogen in Semiconductors, Semiconductors and Semimetals vol. 34 (Academic, NY, 1991)

11. Ogawa, M., Mechanism of high Sidoping into MBE-grown GaAs, Inst. Phys. Conf. Ser. 79, 103-108 (1985) 
12. Walukiewicz, W., Amphoteric native defects in semiconductors, Appl. Phys. Lett. 54, 2094-2096 (1989)

13. Walukiewicz, W., Intrinsic limitations to the doping of wide-gap semiconductors, Physica B302-303, 123 (2001)

14. Schubert, E. F., Stark, J. B., Chiu, T. H. and Bell, B., Diffusion of atomic silicon in gallium arsenide, Appl. Phys. Lett. 53, 293-295 (1988)

15. Bosker, G., Stolwijk, N. A., Thordson, J., Sodervall, U., and Andersson, T. G., Diffusion of Nitrogen from a Buried Doping Layer in Gallium Arsenide Revealing the Prominent Role of As Interstitials, Phys. Rev. Lett., 81, 3443-3446 (1998)

16. Walukiewicz, W., Application of the amphoteric native defect model to diffusion and activation of shallow impurities in III-V semiconductors, Mat. Res. Soc. Symp. Proc. 300, 421-432 (1993)

17. Yu, K. M. et al., Enhanced nitrogen incorporation by pulsed laser annealing of $\mathrm{GaN}_{\mathrm{x}} \mathrm{As}_{1-\mathrm{x}}$ formed by $\mathrm{N}$ ion implantation, Appl. Phys. Lett. 80, 3958-3960 (2002) 


\section{FIGURE CAPTIONS}

Fig. 1 Resistivities (a) and electron concentrations (b) of GaAs:Si and $\mathrm{GaN}_{0.015} \mathrm{As}_{0.985}$ as a function of annealing temperature for $10 \mathrm{sec}$. The Si concentration in these films is $\sim 1.6 \times 10^{19} \mathrm{~cm}^{-3}$. The dependence of electron concentration on annealing temperature (for 10sec) for a $\mathrm{Ga}_{0.93} \operatorname{In}_{0.03} \mathrm{~N}_{0.017} \mathrm{As}_{0.93}$ film doped with $\sim 9 \mathrm{x} 10^{19} \mathrm{~cm}^{-3}$ $\mathrm{Si}$ atoms and a Se doped MOCVD-grown $\mathrm{GaN}_{0.012} \mathrm{As}_{0.988}$ film are also included in 1(b).

Fig. 2 The band gap energies of two Ga0.93 $\mathrm{In}_{0.03} \mathrm{~N}_{0.017} \mathrm{As}_{0.93}$ films doped with $\sim 1.6 \times 10^{19} \mathrm{~cm}^{-3}$ and $9 \times 10^{19} \mathrm{~cm}^{-3} \mathrm{Si}$ atoms measured by photomodulated reflectance (PR) as a function of $10 \mathrm{sec}$ rapid thermal annealing (RTA) temperature.

Fig. 3 Photoluminescence (PL) measurements at room temperature (dotted spectra) and $12 \mathrm{~K}$ (solid spectra) from $\mathrm{GaN}_{0.015} \mathrm{As}_{0.95}$ thin films doped with $\sim 1.6 \times 10^{19} \mathrm{~cm}^{-3} \mathrm{Si}$ atoms.

Fig. 4 PR spectra from Si-doped and undoped $\mathrm{GaN}_{\mathrm{x}} \mathrm{As}_{1-\mathrm{x}}$ samples synthesized by $\mathrm{N}+\mathrm{Si}$ and only $\mathrm{N}$ implantation, respectively, after PLA with a laser fluence of $0.4 \mathrm{~J} / \mathrm{cm}^{2}$ followed by RTA at $950^{\circ} \mathrm{C}$ for $10 \mathrm{~s}$. 


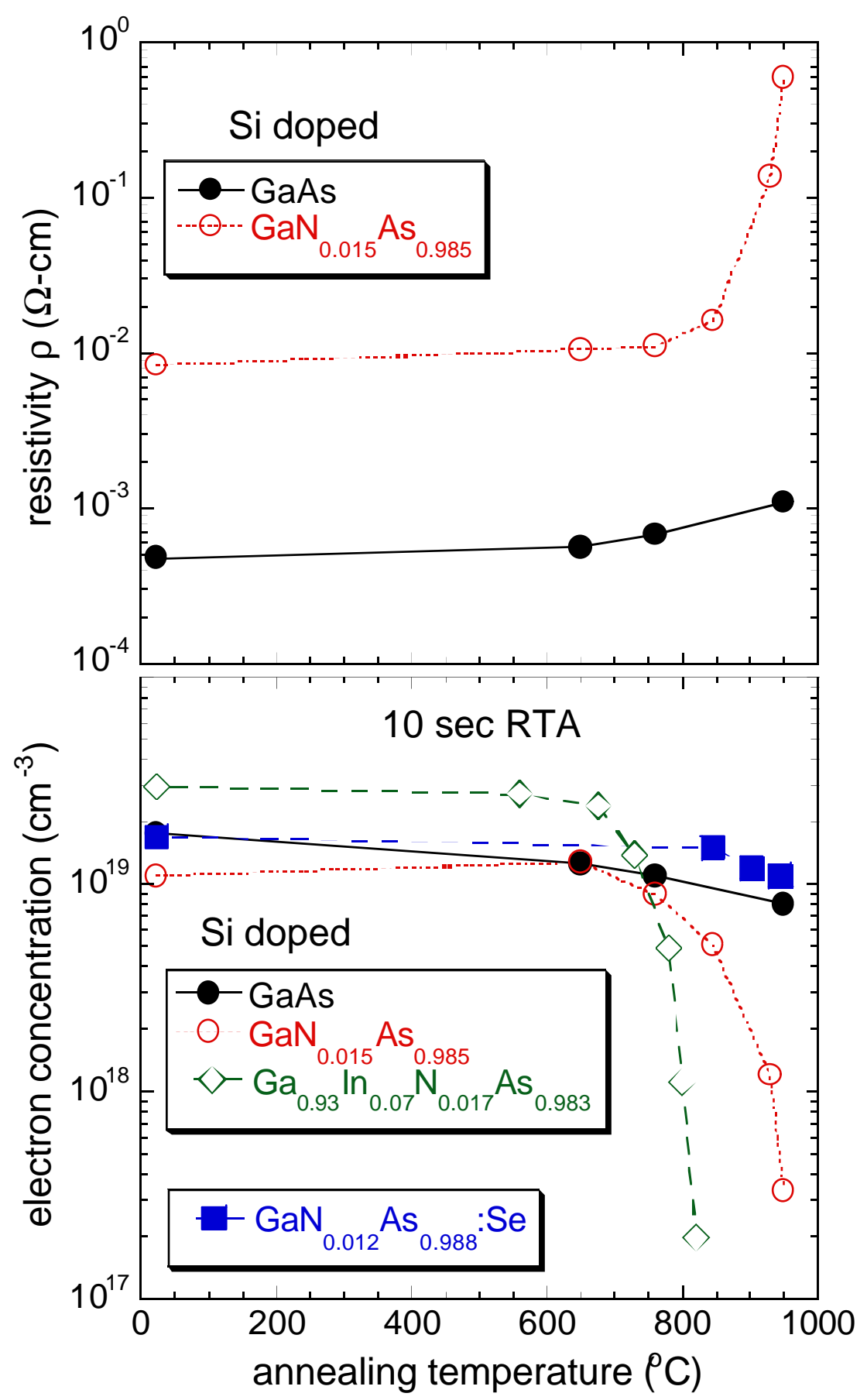

Fig. 1 


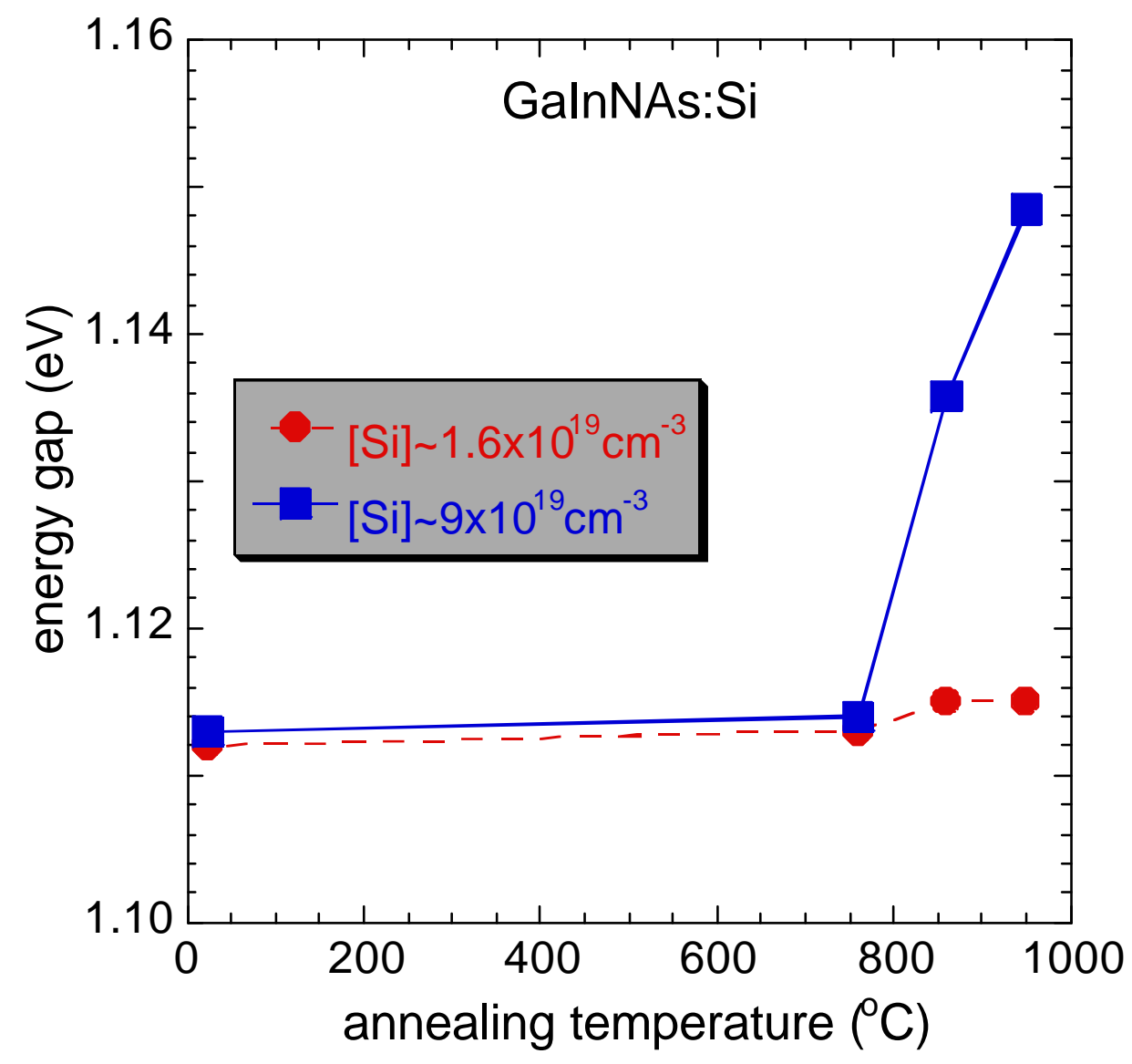

Fig. 2 


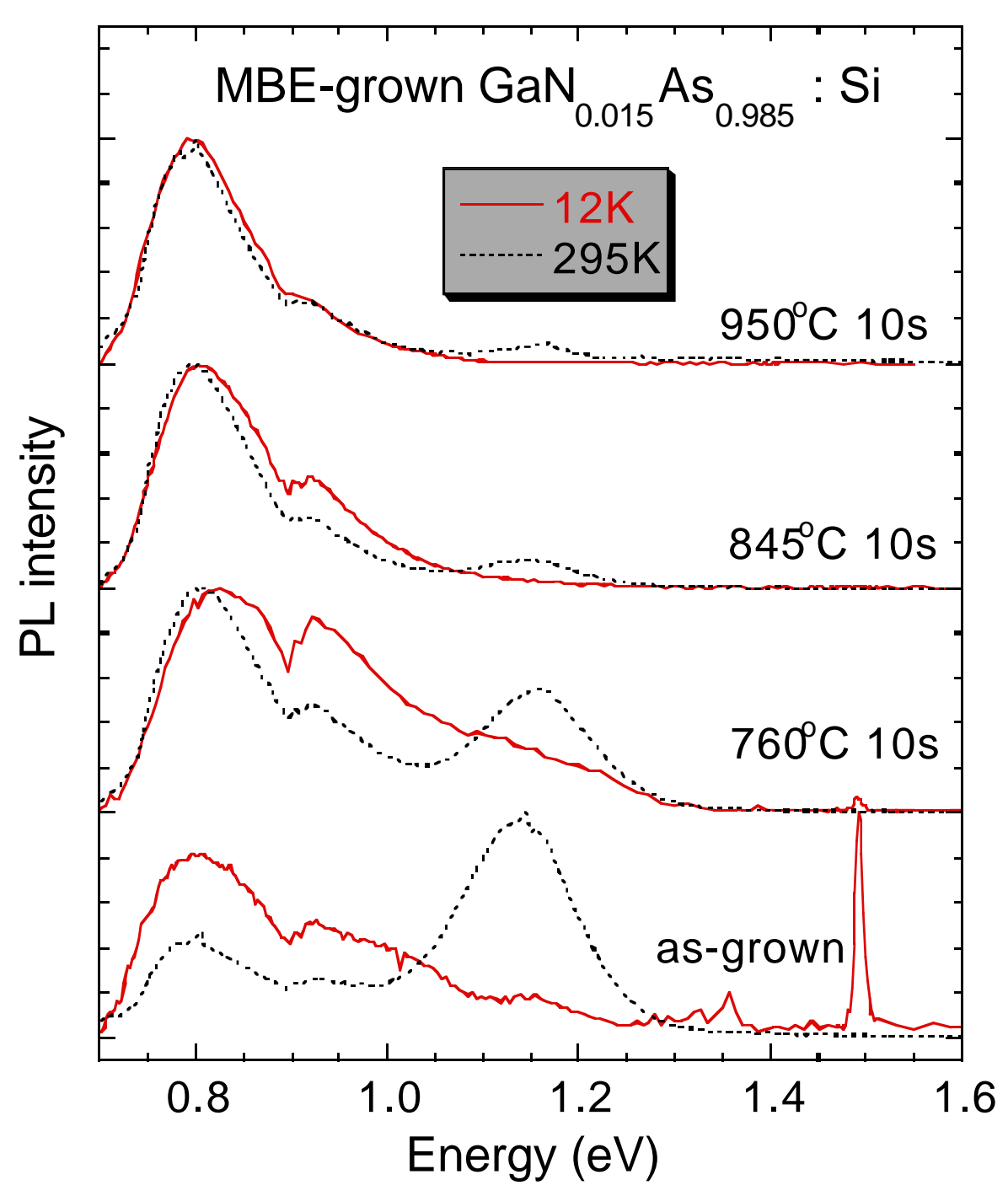

Fig. 3 


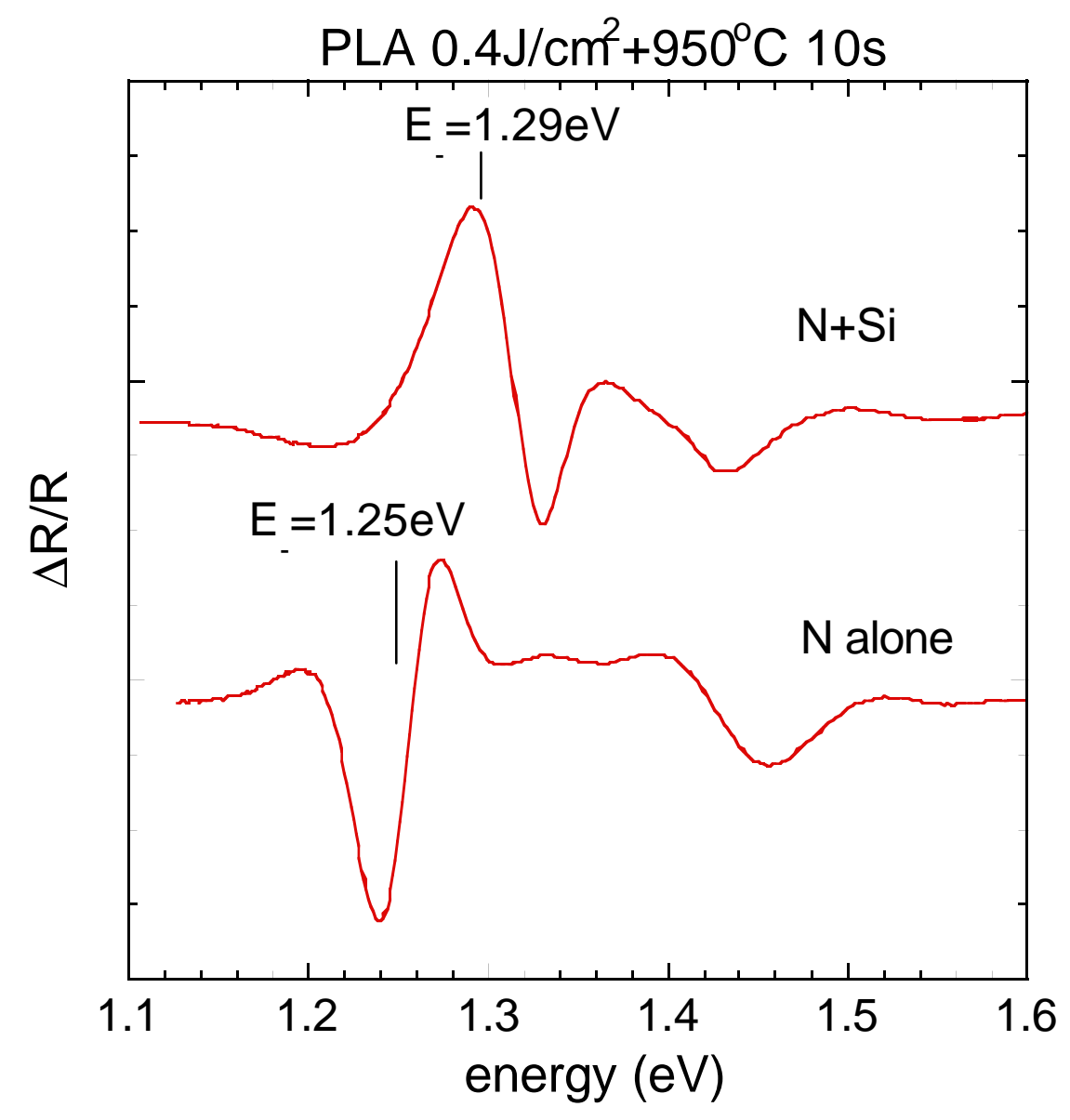

Fig. 4 